\title{
Introduction of new data into the South African Ionospheric Map to improve the estimation of $F 2$ layer parameters
}

\author{
Nicholas Ssessanga ${ }^{1{ }^{\star}}$, Lee-Anne McKinnell ${ }^{2}$, John Bosco Habarulema ${ }^{2}$ \\ ${ }^{1}$ Chunganam National University (CNU), Department of Astronomy and Space Science, Daejeon, South Korea \\ ${ }^{2}$ South African National Space Agency (SANSA) Space Science, Hermanus, South Africa
}

\author{
Article history \\ Received November 20, 2014; accepted March 14, 2015. \\ Subject classification: \\ South African Ionospheric Map (SAIM), F2 layer critical frequency (foF2), IRI-model.
}

\begin{abstract}
In this paper the South African Ionospheric Map (SAIM) is upgraded with the usage of recent International Reference Ionosphere (IRI)-2012 model and South African Bottomside Model (SABIM) version 5 and validated for the critical frequency ( $f \circ \mathrm{F} 2$ ) of the F2 layer by comparing the model's output with the measured ionosonde data. The SABIM model is also validated before use in the SAIM. The ionosonde stations used in the analysis include; Grahamstown $\left(33.2^{\circ} \mathrm{S}, 26.3^{\circ} \mathrm{E}\right)$, Hermanus $\left(34.4^{\circ} \mathrm{S}\right.$, $\left.19.2^{\circ} \mathrm{E}\right)$, Louisvale $\left(28.5^{\circ} \mathrm{S}, 21.2^{\circ} \mathrm{E}\right)$ and Madimbo $\left(22.4^{\circ} \mathrm{S}, 30.9^{\circ} \mathrm{E}\right)$. The analysis of the results showed that the updates improved the performance of SAIM by $75 \%$ over the first version. The foF 2 estimates from the SABIM version 5 model also gave a better estimate to the ionosonde measurements compared to the IRI-2012 model. The SABIM model performed $27 \%$ better than the IRI-2012 model during solar maximum and $14.7 \%$ better during solar minimum.
\end{abstract}

\section{Introduction}

An ionospheric map is essentially a computer program that produces spatial and temporal representations of ionospheric parameters like electron density, critical plasma frequencies, etc. for every geographical location on the map [Okoh et al. 2010]. The South African Ionospheric Map (SAIM) was developed to predict the variation of the ionosphere over the South African region (ranging $12^{\circ}-40^{\circ} \mathrm{S}, 10^{\circ}-40^{\circ} \mathrm{E}$ ) using the available ionospheric data sources, namely the South African ionosonde network, the International Reference Ionosphere (IRI-2007) model and South African Bottomside Ionosphere Model (SABIM, version 3). The objective of the SAIM project was to develop a tool that could help radio communication companies in South Africa to correct for ionospheric effects and also improve direction finding in HF radio sounding. Other works have attempted to improve the estimation of ionospheric parameters over the South African region. For example, Poole and Poole [2002]; McKinnell and
Poole [2004b] applied the Neural Network (NN) technique in modelling the $\mathrm{F} 2$ layer critical frequency (foF2) over the South African region. Opperman et al. [2007] developed a Global Positioning System (GPS)-based, variable degree adjusted spherical harmonic (ASHA) model for near real-time regional ionospheric Total Electron Content (TEC) mapping over South Africa. Habarulema and McKinnell [2012]; Habarulema et al. [2007, 2011] did studies related to the development of a NN based model for the prediction of South African GPS derived TEC. Ssessanga et al. [2014] described a statistical method (TEC2F2, which proved to be more accurate than IRI-2012) of estimating the foF2 values from GPS Vertical TEC over South Africa.

SAIM was developed to produce maps of TEC, foF 2 and the electron density profiles for a given set of input parameters. This paper focuses on the upgrade of the SAIM (with the new IRI-2012 model and the version 5 of the SABIM model) and the validation of the results. The SABIM (version 5), hereafter referred to as SABIM, is also validated before use in SAIM.

\section{South African ionosonde network}

Figure 1 shows the map of South Africa indicating the location of the 4 ionosondes. The data collected from the South African ionosonde network is sent in real time to a central archiving centre at the South African National Space Agency (SANSA) in Hermanus. The information is published on the web and made available to the global community, via various websites, including the Space Physics and Interactive Data Resource (SPIDR) and the Digital Ionogram Database (DIDBASE) [McKinnell 2008b].

In SAIM the ionosonde data is recorded in the SAO.XML file format (which is a physical data format for the ionogram-derived data). SAO stands for Stan- 


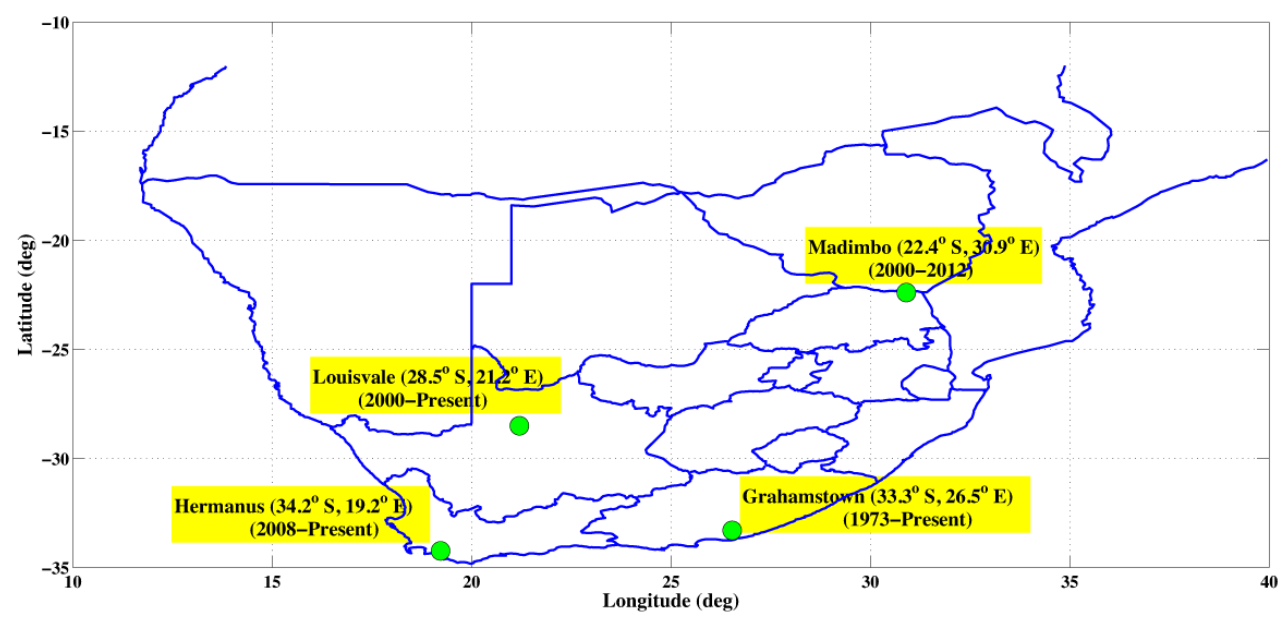

Figure 1. A map showing the South African ionosonde network.

dard Archival Output and XML for eXtensible Markup Language. Once SAO.XML is generated, the document holds a single element SAORecordList that may have multiple sub-elements, each corresponding to one set of ionogram-derived data obtained for one ionogram [Reinisch et al. 2012].

During the development of the first version of SAIM, the SAO.XML data from Louisvale and Madimbo stations had a resolution of 30 minutes while Grahamstown and Hermanus stations had a 15 minute resolution, and so the SAIM was set to a temporal resolution of 30 minutes. Currently, all the ionosondes are set to a 15 minute resolution and so is the current version of SAIM.

\section{SABIM improvement and validation}

SABIM is a South African regionally based bottomside ionosphere model. The model was developed with the primary aim of addressing the inaccuracies of ionospheric modelling over the South African region [McKinnell and Poole 2004a]. The first version of the SABIM model was called the LAM model and was developed using data from one station (Grahamstown, $33.3^{\circ} \mathrm{S}, 26.5^{\circ} \mathrm{E}$ ). This station at that time had the largest database, covering over 30 years of ionospheric observations. The large database influenced the decision to use the NN technique, which requires a large archived database describing the history of the relationship between the input and the required output parameters [McKinnell 2003]. The outputs were the values of the parameters required for constructing the bottomside ionosphere profile. The results of the LAM model were more successful at predicting the electron density profile for a particular set of inputs than the IRI model [McKinnell 2003]. The IRI model is an internationally recognized model and the recommended standard model for prediction of plasma parameters in the Earth's ionosphere [Bilitza et al. 2011]. This global model is continuously improved with new data by a group of experts spanning the globe [Bilitza and Reinisch 2008]. However, the model still fails to predict accurately during both quiet and disturbed conditions over regions, such as the African sector, where there is an historic paucity of ionospheric data [e.g., McKinnell and Poole 2004b, Adewale et al. 2011, Okoh et al. 2012, Habarulema et al. 2013].

With time the South African ionosonde network was expanded to include two more ionosondes that were installed at Louisvale $\left(28.5^{\circ} \mathrm{S}, 21.2^{\circ} \mathrm{E}\right)$ and Madimbo $\left(22.4^{\circ} \mathrm{S}, 30.9^{\circ} \mathrm{E}\right)$. This led to the expansion of the LAM model to include additional data for regional representation. The model was renamed SABIM and the initial input parameters (year, day number and hour, in Universal Time, UT) were modified to include geographic latitude and longitude. During operation, SABIM uses the year input to calculate the suitable solar (1-month (R1) and 2-months (R2) running mean of sunspot number) and magnetic (daily (A8) and 2-day (A16) running mean of magnetic index values) variables (based on provided files containing the daily values of each) while inputs day number and hour are used to determined the seasonal and the diurnal variation respectively [McKinnell and Poole 2004a]. The SABIM model also provides an option where the year may not be entered such that the solar and magnetic activity variables can be entered instead. In the case where the solar and magnetic variables are entered, the model determines a suitable year based on the given solar variable, and determines the magnetic dip angle and declination for that year. When this model is implemented in the field the source for the inputs is adjusted to suit the environment within which the model is run [Poole and McKinnell 2000]. In this study the choice of using year, day number and hour as inputs is utilised. Since its inception most versions of the SABIM model were trained with data from only three ionosonde locations: Grahamstown, Louisvale and Madimbo. The ionosonde network has now grown to include data from Hermanus which was a previously unrepresented area. 


\begin{tabular}{cc} 
Station & Data inclusion in SABIM \\
\hline Grahamstown & $1973-2010$ \\
Louisvale & $2000-2010$ \\
Madimbo & $2000-2010$ \\
Hermanus & $2008-2010$ \\
\hline
\end{tabular}

Table 1. Time range of ionosonde data used in training SABIM.

The SABIM was updated with this additional data, covering a period 2008 to 2010 (from all four ionosondes) and the NN retrained. 25 networks were used in the routines that calculate the F2 and the F1-F2 coefficients as in all the other profile parameters. This in turn improves the smoothing routine to ensuring a continuous smooth profile across the F1-F2 boundary [McKinnell and Sibanda 2010]. The output from SABIM is the electron density profile which best represents the average ionospheric behaviour that could be expected for the given input parameters. In this paper however, the SABIM model is only validated for the critical frequency (foF2) of the F2 layer by comparing the model's output with the measured ionosonde data and the IRI-2012 model during different diurnal, seasonal and solar cycle conditions. The data set used in the analysis covers the period 2000 to 2010 . However, note should be taken that although a comparison between SABIM and IRI-2012 is performed, the newly trained/updated SABIM includes new data, which is not available to the IRI-2012 model. Table 1 shows the status of SABIM with regards to data inclusion from the four ionosonde stations.

\subsection{Diurnal variation}

Figure 2 shows the diurnal variation of the foF 2 values from the SABIM model, the IRI-2012 model and the four ionosondes stations (Grahamstown, Louisvale, Madimbo and Hermanus). During equinox (Figure 2a) in March and solstice (Figure 2b) in June of 2010, the SABIM model shows an improved prediction of the foF2 values over the IRI-2012 model between 06:00 UT and 15:00 UT (South African Standard Time, SAST = $\mathrm{UT}+2)$. This is very evident at the Hermanus station where the IRI-2012 model is seen to underestimate and
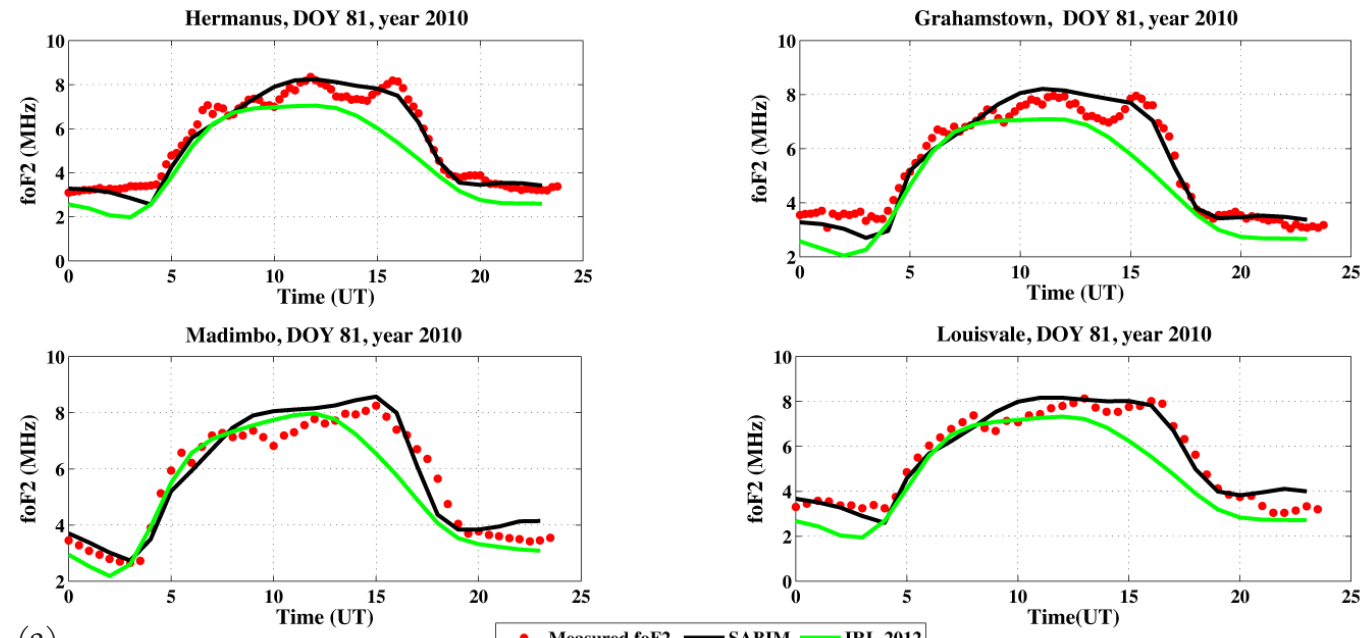

(a)
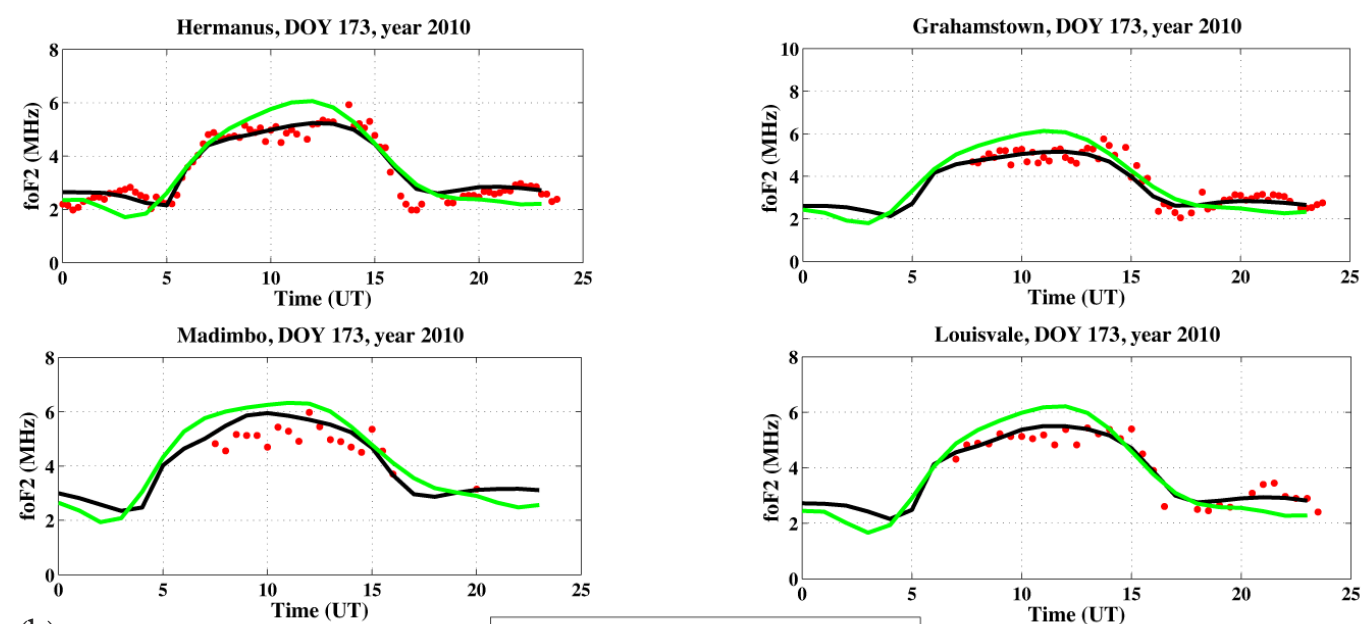

(b)

Figure 2. A comparison of diurnal foF2 values from the SABIM model, the IRI-2012 model and the ionosondes (Hermanus, Grahamstown, Louisvale and Madimbo). (a) Equinox in March (Day of Year (DOY) 81) 2010, and (b) solstice in June (DOY 173) 2010. 

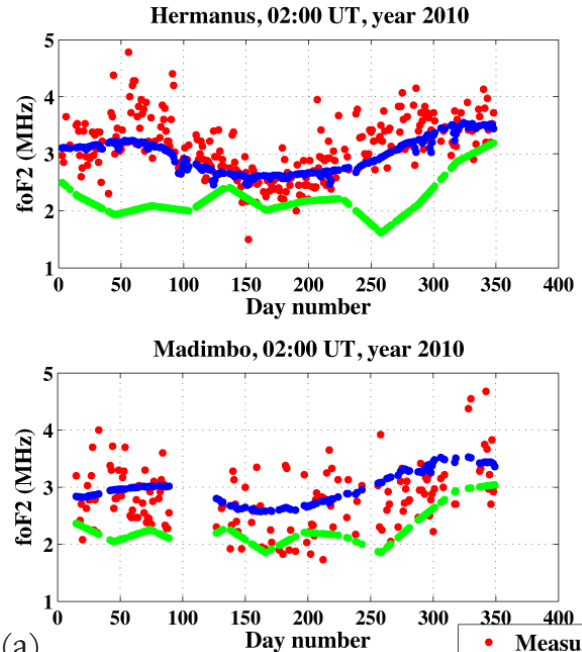

(a)
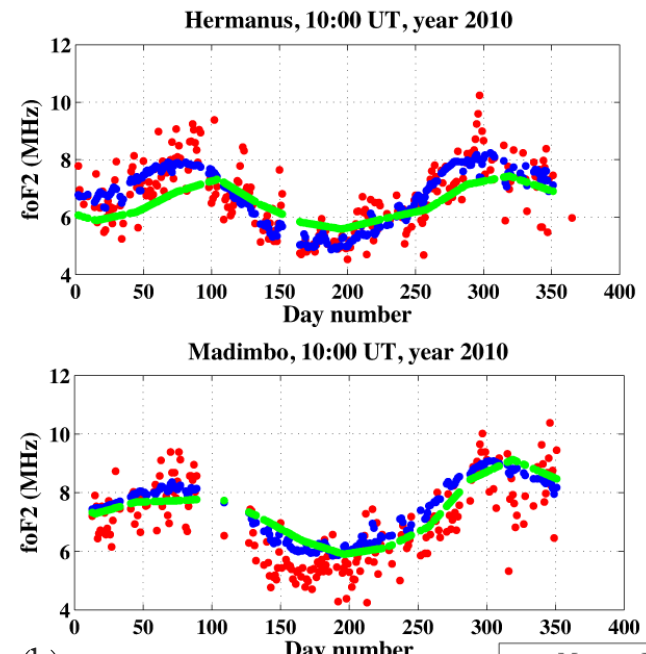

(b)
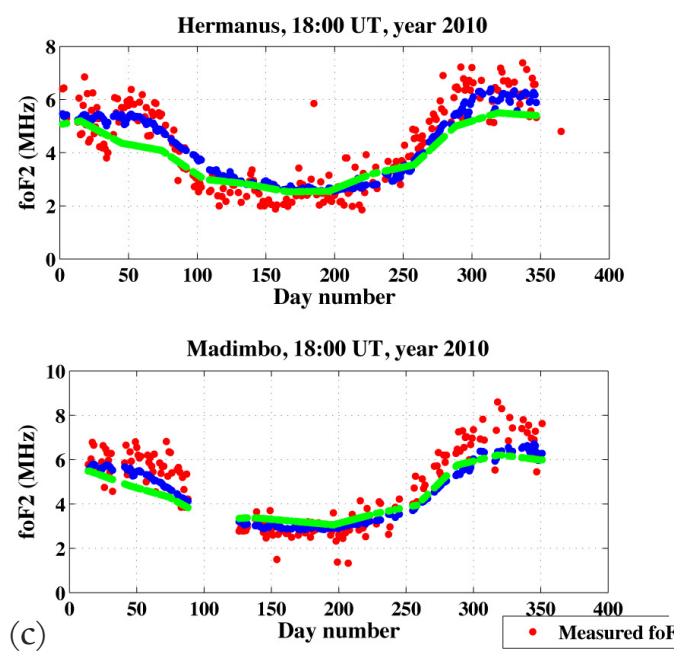

(c)

Figure 3. Annual variation of foF2 values from the ionosondes (Hermanus, Grahamstown, Louisvale and Madimbo), the SABIM model and the IRI-2012 model. (a) Before sunrise 02:00 UT (04:00, SAST), (b) local noon 10:00 UT (12:00, SAST) and (c) after sunset 18:00 UT (20:00, SAST).

overestimate the foF2 values during equinox and solstice respectively.

\subsection{Seasonal variations}

Figure 3 shows a plot of annual foF2 values from the SABIM model, the IRI-2012 model and the four
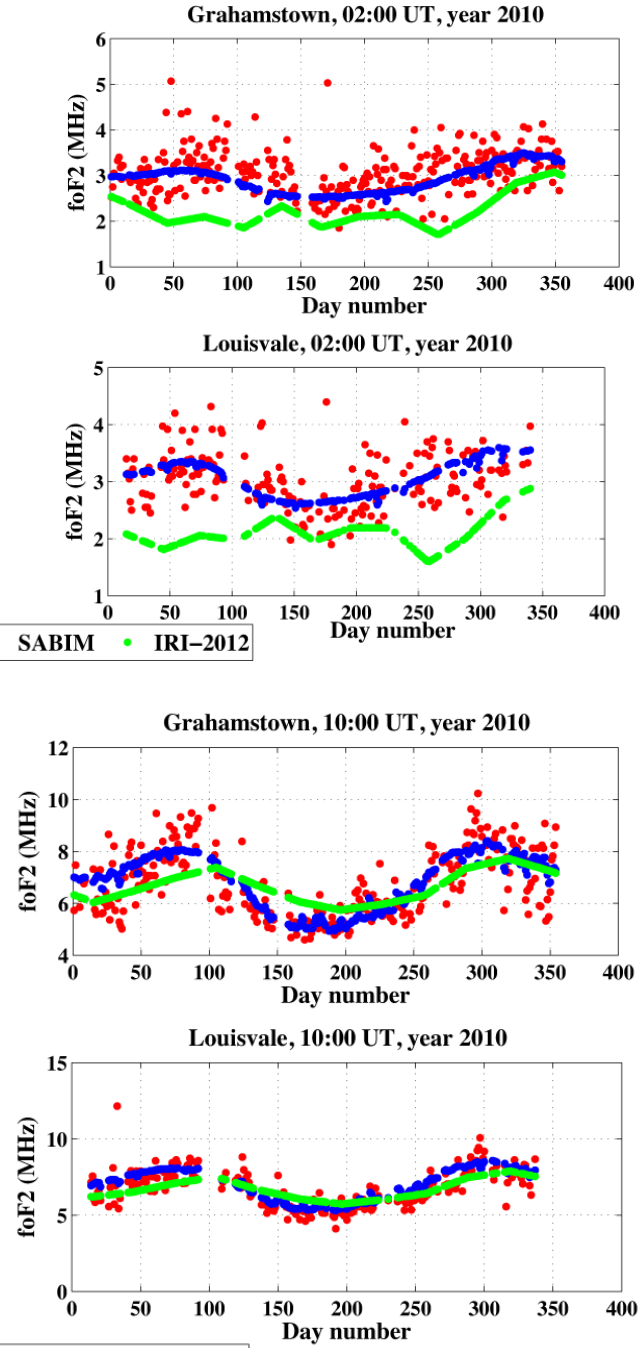

- SABIM $\bullet$ IRI-2012
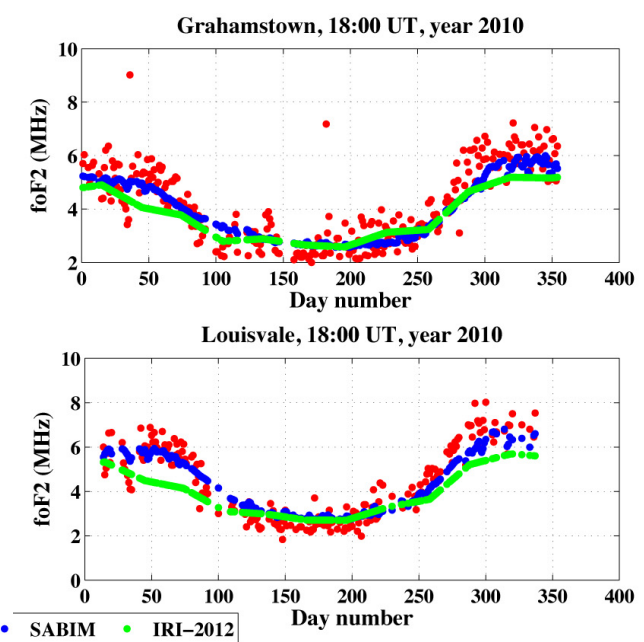

ionosonde stations, before local sunrise (02:00 UT), noon (10:00 UT) and after sunset (18:00 UT) in 2010.

At local sunrise (Figure 3a) the IRI-2012 model shows an underestimation of the foF2 values throughout the year, whereas the SABIM model produces a more accurate estimation. This is observed at all four 
ionosonde stations.

At local noon (Figure 3b) and sunset (Figure 3c) both models, SABIM and IRI-2012, show a good estimation of the foF 2 values. However, at local noon the seasonal changes are well-defined and so a further analysis of these results was performed. Residues of the measured foF 2 values and the output from each of the models were determined for the local noon time at all four stations as shown in Figure 4. The results were then binned according to the days of the year, $0-100$, 101-250 and 251-365. The data in each bin for every station was averaged and the overall mean for the four stations also determined. The results are given in Table 2. The results show that the SABIM model performs better than the IRI-2012 model both during summer (DOY, $0-100)$ and winter (DOY, 101-250). This is most visible at the Grahamstown and Hermanus stations. The overall average values indicate that the SABIM model performs better during winter than during summer.

The Root Mean Square Error (RMSE) was determined from the residues at each ionosonde location and the overall average determined. Equation (1) shows the method used for analysis,

$$
\operatorname{RMSE}=\sqrt{\frac{\sum_{\mathrm{j}}^{\mathrm{n}}\left(\mathrm{foF}_{\mathrm{j}}-\mathrm{foF} 2 \mathrm{SABIM}_{\mathrm{j}}\right)^{2}}{\mathrm{n}}},
$$

where foF $2_{j}$ is measured foF 2 values from ionosonde, foF2_SABIM ${ }_{j}$ is foF 2 values from the SABIM model, $n$ is the total number of measured foF 2 values and $j=1,2$, $3, \ldots, n$. The SABIM model performed better than the IRI-2012 model, with a RMSE of $0.8 \mathrm{MHz}$ compared to $0.9 \mathrm{MHz}$ of the IRI-2012 model. In addition, the new version of SABIM performs $16 \%$ better than its predecessors presented in the work by McKinnell and Poole [2004a]. Furthermore, although the SABIM model out performs the IRI-2012, the IRI-2012 model should be credited for performing better during the unexpected 2010 deep solar minimum.

\subsection{Solar cycle variation}

For this validation, data from the years 2000 and 2006 were chosen to represent solar maximum and solar minimum respectively and the 10:00 UT foF2 values


Figure 4. Annual variation of residues between the measured local noon (10:00 UT) foF2 values and the output from the models (SABIM and IRI-2012) for all 4 ionosonde stations.

\begin{tabular}{ccccccc} 
& DOY & $\begin{array}{c}\text { Grahamstown } \\
(\mathbf{M H z})\end{array}$ & $\begin{array}{c}\text { Hermanus } \\
(\mathbf{M H z})\end{array}$ & $\begin{array}{c}\text { Madimbo } \\
(\mathbf{M H z})\end{array}$ & $\begin{array}{c}\text { Louisvale } \\
(\mathbf{M H z})\end{array}$ & $\begin{array}{c}\text { Average } \\
(\mathbf{M H z})\end{array}$ \\
\hline SABIM & $0-100$ & -0.093 & -0.218 & -0.185 & -0.291 & -0.197 \\
& $101-250$ & 0.114 & 0.015 & -0.667 & -0.158 & -0.174 \\
& $251-365$ & -0.119 & -0.070 & -0.505 & -0.372 & -0.266 \\
IRI-2012 & $0-100$ & 0.808 & 0.700 & 0.108 & 0.108 & 0.431 \\
& $101-250$ & -0.228 & -0.423 & -0.669 & -0.377 & 0.424 \\
& $251-365$ & 0.483 & 0.348 & -0.352 & 0.275 & 0.188
\end{tabular}

Table 2. Mean difference between measured foF2 values and results from models, SABIM and IRI-2012, based on the DOY in 2010. 
were chosen for analysis.

Figure 5 shows a plot of the 10:00 UT foF 2 values from the three ionosonde stations (Grahamstown, Madimbo and Louisvale), and the SABIM and IRI-2012 models during solar maximum (Figure 5a) and during solar minimum (Figure $5 \mathrm{~b}$ ). The Hermanus ionosonde was omitted in this analysis since the station did not exist during that period. The output from both models was down-sampled to match the measured foF 2 data. Therefore, the gaps in the plots are a result of missing ionosonde values.

The RMSE values were determined during solar maximum and during solar minimum at the three ionosonde stations. The results (see Table 3 ) show that both models (SABIM and IRI-2012) perform better during solar minimum than during solar maximum. Furthermore, the SABIM model performed $27 \%$ better than the IRI-2012 model during solar maximum (using only the Grahamstown station with the most continuous data) and better $14.7 \%$ during solar minimum (using
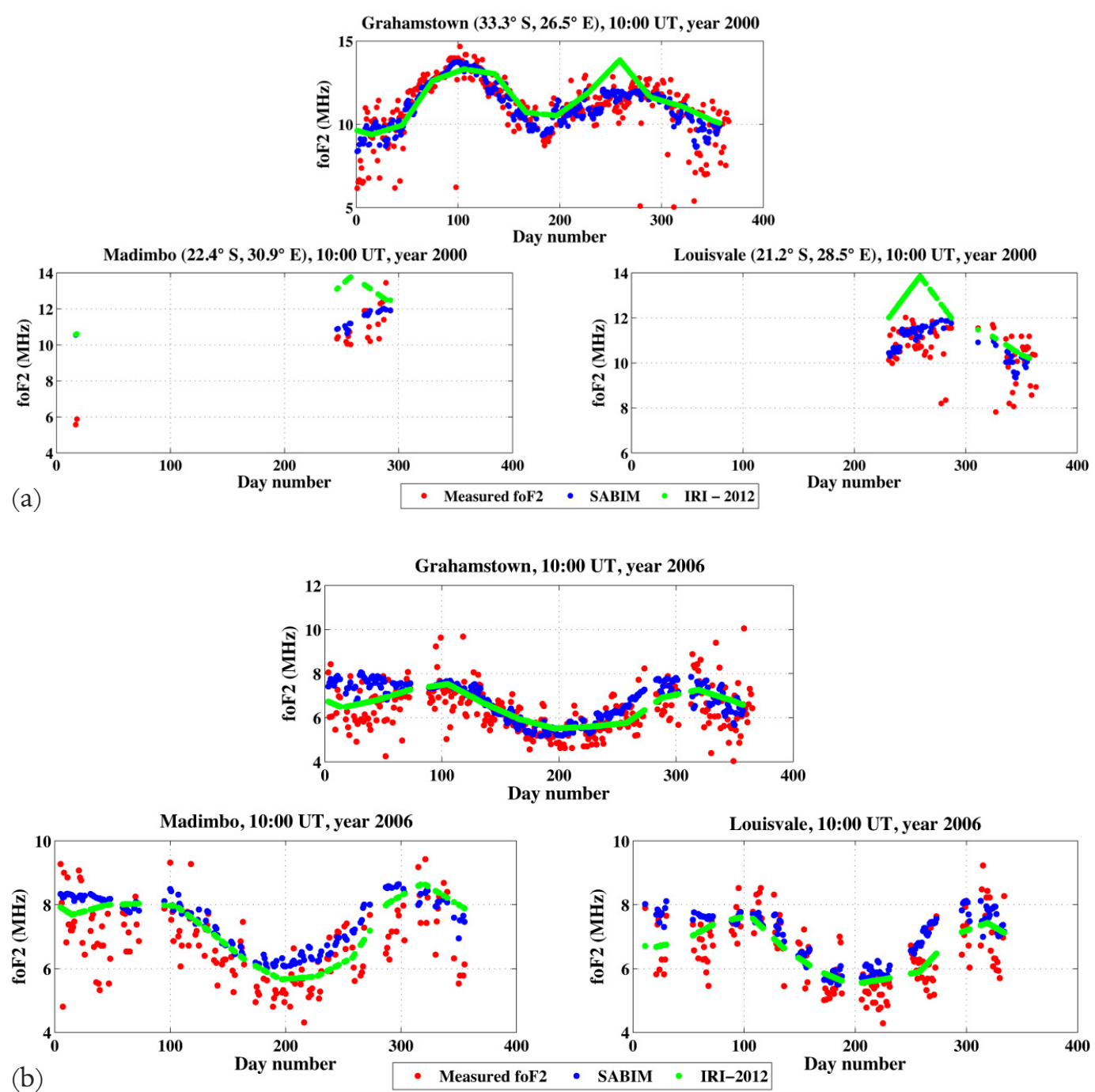

Figure 5. Ionosondes (Grahamstown, Madimbo and Louisvale), SABIM and IRI-2012 10:00 UT foF2 annual variation. (a) During solar maximum and (b) during solar minimum.

\begin{tabular}{cccccc} 
& Year & $\begin{array}{c}\text { Hermanus } \\
(\mathbf{M H z})\end{array}$ & $\begin{array}{c}\text { Grahamstown } \\
(\mathbf{M H z})\end{array}$ & $\begin{array}{c}\text { Louisvale } \\
(\mathbf{M H z})\end{array}$ & $\begin{array}{c}\text { Madimbo } \\
(\mathbf{M H z})\end{array}$ \\
\hline SABIM RMSE & 2000 & - & 1.047 & 0.966 & 0.592 \\
& 2006 & - & 0.825 & 0.695 & 0.994 \\
IRI-2012 RMSE & 2000 & - & 1.435 & 1.911 & 0.709 \\
& 2006 & - & 0.939 & 0.910 & 1.103 \\
\hline
\end{tabular}

Table 3. RMSE for the SABIM and IRI-2012 model for the years 2000 (solar maximum) and 2006 (solar minimum). 
data from three stations, Grahamstown, Madimbo and Louisvale). The percentage performance was calculated using Equation (2).

$\%$ improvement $=$ $\left(\frac{\text { Average SABIM(RMSE) }- \text { Average IRI-2012(RMSE) }}{\text { Average IRI-2012(RMSE })} \times 100\right)$
Scatter plots were generated for the measured foF2 values and the output from each of the two models during solar maximum (Figure $6 \mathrm{a}$ ) and during solar minimum (Figure $6 \mathrm{~b}$ ). A line of best fit (y) was inserted in each plot and the correlation coefficient $(\mathrm{R})$ determined at each station.

During solar maximum (again using data from only the Grahamstown station), the SABIM model gave
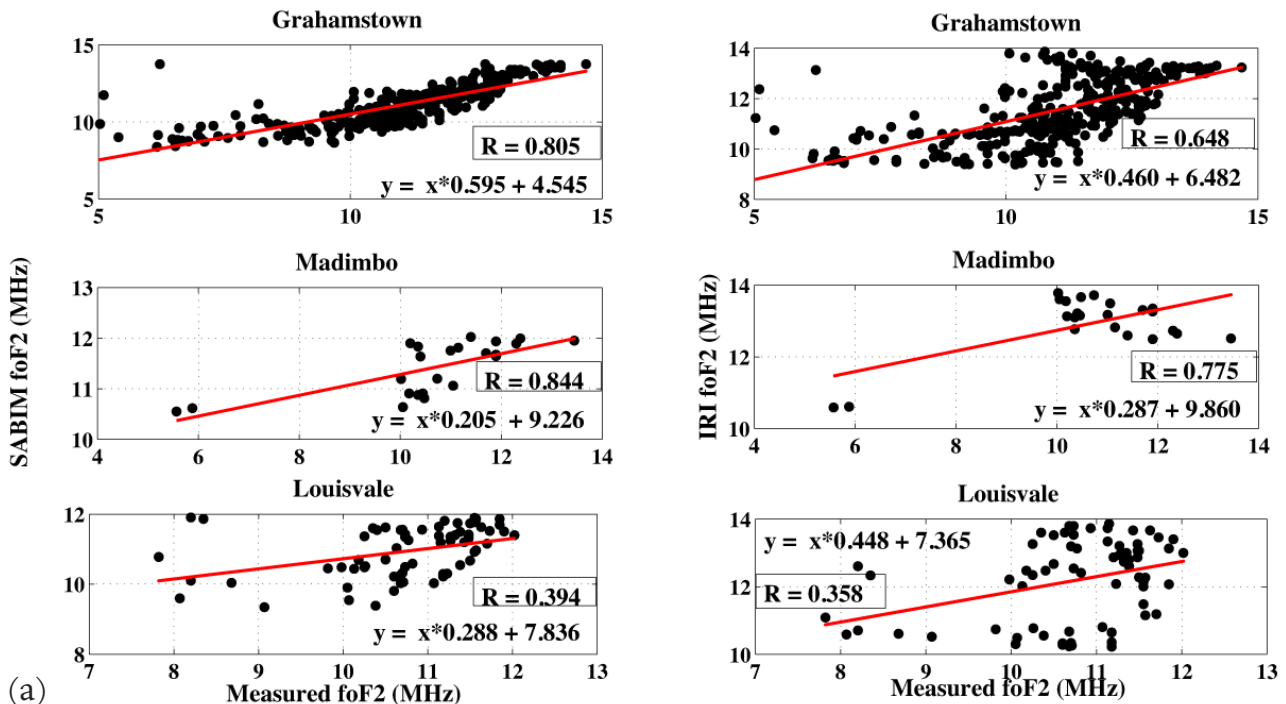

(a)
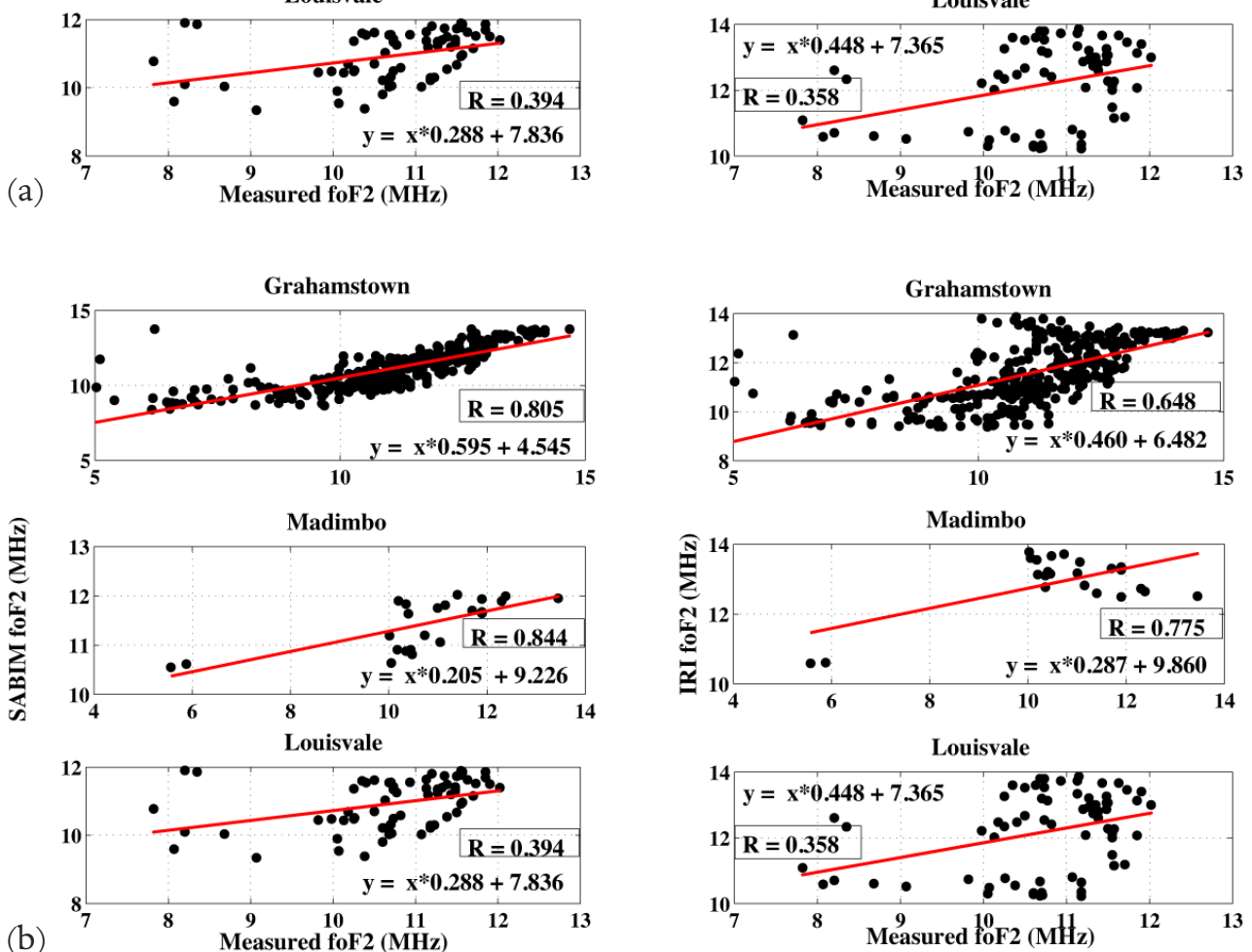

Figure 6. Scatter plots of annual foF2 values during solar maximum (Figure 6a) and solar minimum period (Figure 6b) at three ionosonde stations, Grahamstown, Madimbo and Louisvale. The left and right panels represent results from the SABIM model and the IRI-2012 model respectively.

SABIM

Windows version number

Exit time

Elapsed time

Process time
Old

Windows NT 5.1 (Build 2600)

4:11 pm, Sunday, July, 2012

0:04:33.812 HH:MM

0:04:12.078 HH:MM
New

Windows NT 5.1 (Build 2600)

4:03 pm, Sunday, July, 2012

0:01:24.687 HH:MM

0:01:04.875 HH:MM

Table 4. Run times of the new and old SABIM models. 
a higher $\mathrm{R}$ value of approximately 0.80 compared to 0.65 by the IRI-2012 model. During solar minimum (using all three stations) both models displayed an average $\mathrm{R}$ value of approximately 0.65 .

\subsection{SABIM run time}

The old and new versions ( 4 and 5 respectively) of SABIM were set to run the same task under the same conditions and the run time determined. The results displayed in Table 4 indicate that the new version of SABIM is 4 times faster than the old version. This faster processing time will in return reduce the response time of SAIM.

\section{Use of SABIM, IRI-2012 and ionosonde data in SAIM}

\subsection{SABIM and IRI-2012}

For the purpose of using the two models in this work, executable programs were created from the Fortran (IRI-2012) and C++ (SABIM) codes using the gcc and Microsoft Visual C ++2010 compilers respectively.

The use of the SABIM model in SAIM was previously limited to a triangular region formed by the three ionosonde stations, Grahamstown, Madimbo and Louisvale, the data of which had been used during the model development [McKinnell 2008a]. The newer version of SABIM has been trained by data from four ionosonde stations, thus expanding the region covered by the SABIM model to a quadrilateral region as shown in Figure 7.

The IRI-2012 model was used outside of the quadrilateral region. Furthermore, a smoothing function was introduced at the boundary of the two models such that the SABIM model still contributed outside of the quadrilateral region. The smoothing function used is

$$
f=f_{s} \cos ^{2} \beta+f_{i} \sin ^{2} \beta, \beta=\frac{90 d}{1117}
$$

where $f_{s}$ is SABIM's foF2 value for a location outside the quadrilateral region, $f_{i}$ is IRI-2012's corresponding foF2 value for that location, $f$ is the resulting foF 2 value for the location and $d$ is a measure of the point's distance from the closest edge of the quadrilateral [Okoh et al. 2010]. Further information on how the SABIM and IRI2012 models are combined is found in Okoh [2009]. The IRI-2012 model offers two alternatives for the generation of the foF 2 parameter, namely the International Radio Consultative Committee [CCIR 1966] model and the International Union of Radio Science (URSI) model developed by Rush et al. [1989]. Both models use a similar spherical-harmonics-type representation of the

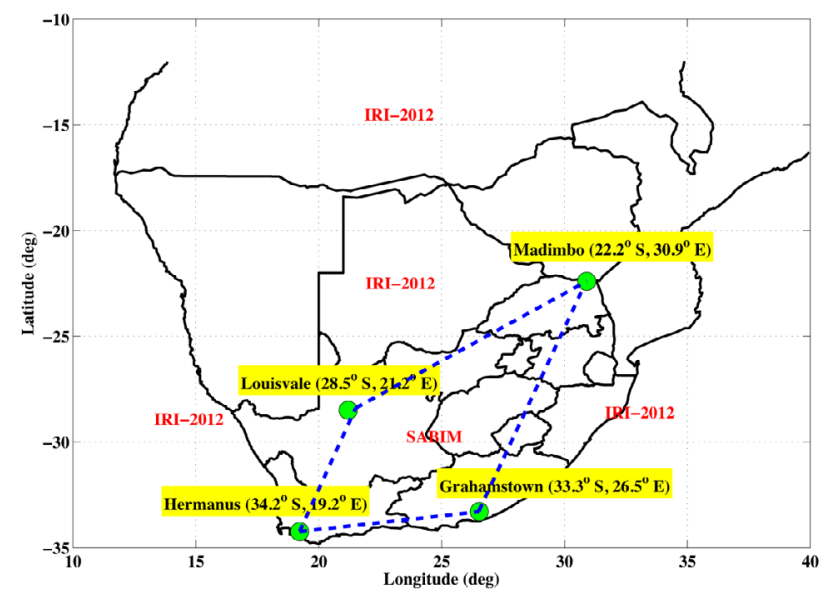

Figure 7. South African map indicating the regions where the SABIM and IRI-2012 models were used in developing the SAIM.

monthly median diurnal variation of foF 2 observed by the worldwide network of ionosondes, but with a different interpolation scheme for the ocean areas. Bilitza et al. [2011] and Adeniyi et al. [2003] mentioned that the CCIR model and the URSI model perform better over the continent and ocean areas respectively. Thus, in this study the CCIR model was used where the IRI2012 model was applied. In addition, the IRI-2012 storm option is set active in the program for better foF2 predictability during storm conditions [Miró Amarante et al. 2007]. However, the results presented in the sequel are during quite days.

\subsection{Ionosonde data}

Measurements by the ionosondes were used to adapt the model output to the ionosonde measurements. In the case of foF 2 map generation, the program calculates the residues of the measured foF 2 and the modelled foF 2 at each ionosonde location, and then fits the best plane by the method of least squares. Depending on the obtained values, the plane values are added to or subtracted from the existing modelled map in order to adapt it to the ionosonde measurements [Okoh 2009].

\section{SAIM validation}

The validation of SAIM was based on the ionospheric foF2 diurnal, seasonal and solar cycle variation. In addition, the electron density profiles generated by the SAIM program were compared to the measured profiles from the ionosondes.

\subsection{Diurnal, seasonal and solar cycle variation}

Figure $8 \mathrm{a}$ and $8 \mathrm{~b}$ show diurnal and seasonal foF2 maps generated by the SAIM program. The diurnal maps were generated using a resolution of 3 hours on an arbitrarily chosen DOY 267, 2010 while seasonal maps were generated at 10:00 UT for 4 days, each correspon- 

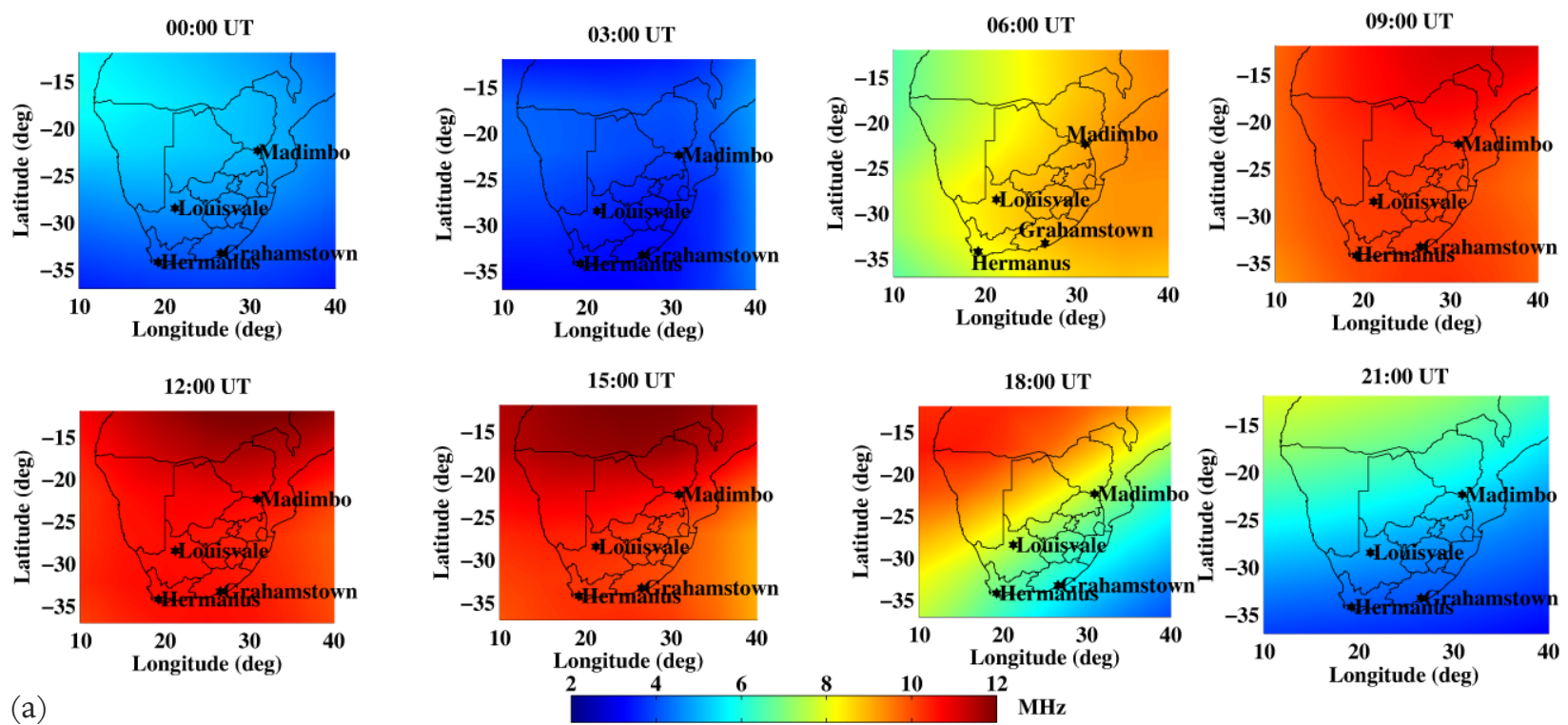

(a)
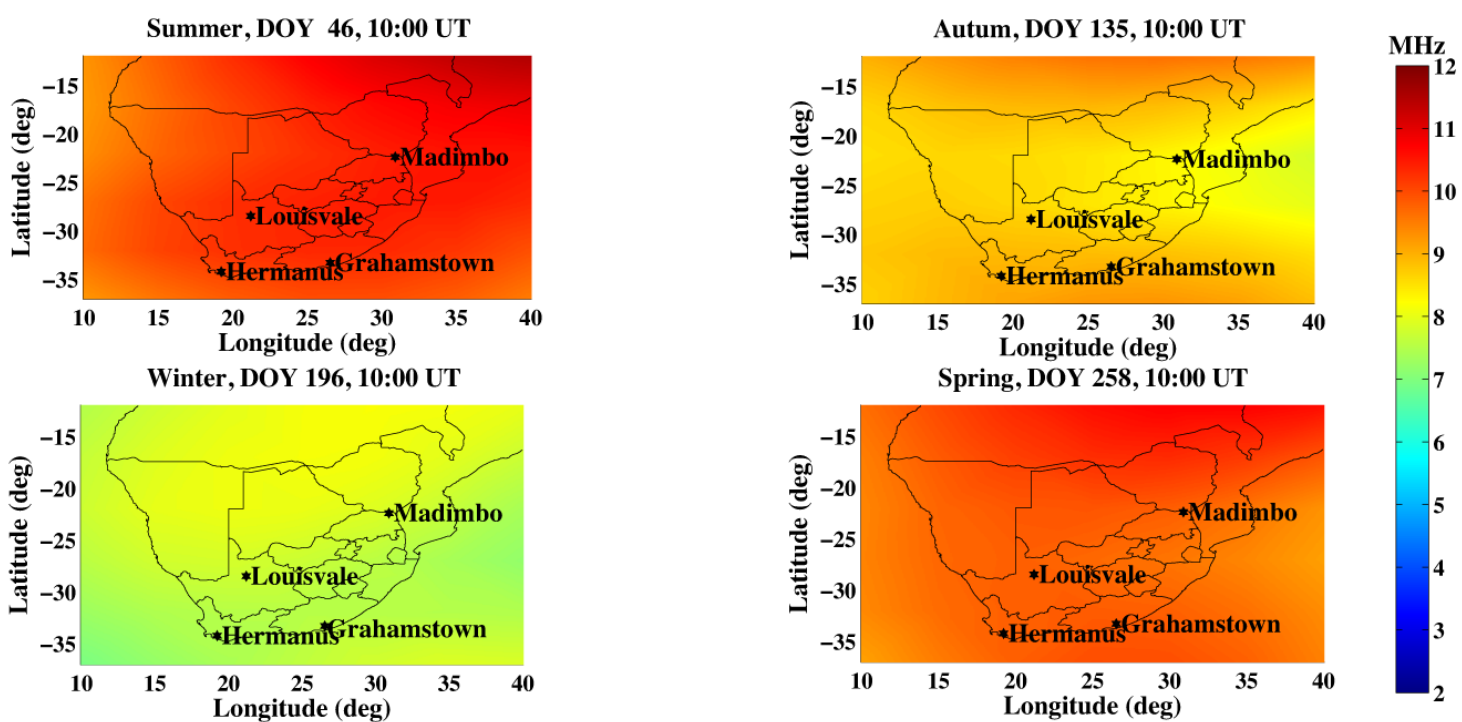

(b)
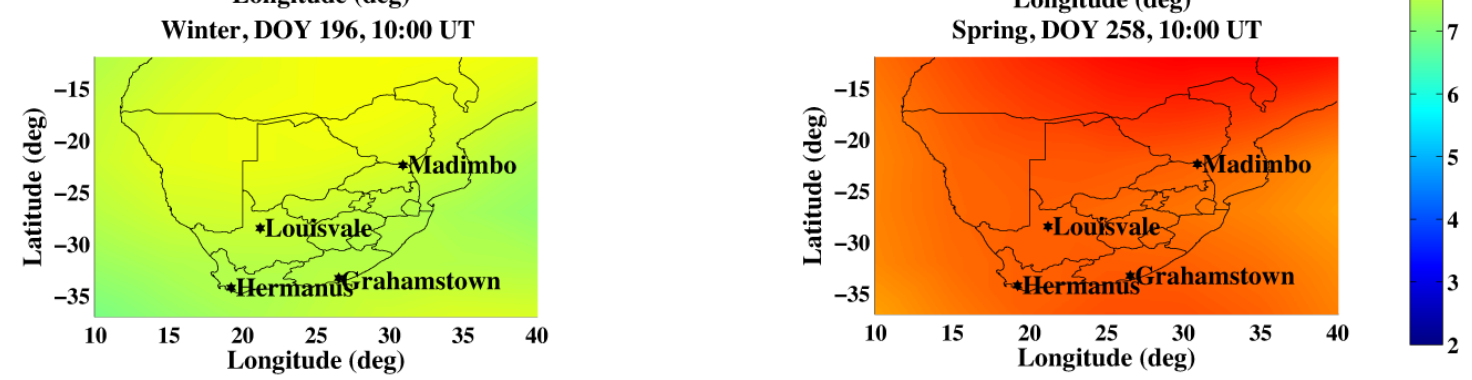

Figure 8. foF2 maps generated by SAIM. (a) Diurnal variation, (b) seasonal variations: summer, autumn, winter and spring in 2010.

ding to a different season (summer (DOY 46), autumn (DOY 135), winter (DOY 196) and spring (DOY 258)) of the year 2010 .

The diurnal maps show the expected variation in foF 2 which increases from low level intensity at night (00:00-03:00 UT), peaks during the day (06:00-15:00 UT) and decreases again after sunset (18:00-21:00 UT). The annual foF2 variation is also well-depicted in the seasonal plots with ionospheric ionisation seen to be more pronounced during summer and least during winter.

Figure 9 shows 10:00 UT foF2 maps generated for an arbitrarily chosen DOY (202) during solar maximum (2000) and during solar minimum (2006). The maps show a distinct difference in the intensity of the foF2. During solar maximum the foF2 values reach $12 \mathrm{MHz}$ as compared to $6 \mathrm{MHz}$ during solar minimum. These variations are due to the amount of solar radiation emitted by the sun being strongest during solar maximum and least during solar minimum.

\subsection{Electron density profiles}

To generate the profiles, the SAIM program passes the calculated (least square solution from combining SABIM, IRI-2012 and ionosondes) foF2 and hmF2 values for any chosen location to the IRI-2012 model as inputs. The IRI-2012 model then uses the inputs to re-adjust and generates the required profile. Figure 10 shows a comparison of the SAIM profiles and the measured profiles from three ionosonde stations (Hermanus, Grahamstown and Louisvale) in different seasons (summer (DOY 45), autumn (DOY 100), winter (DOY 182) and spring (DOY 246)) of 2012 at 10:00 UT. The Madimbo ionosonde station was not included in the analysis since it was not operational during this period due to technical problems.

For each season, the SAIM shows a good estimation of both the foF 2 and hmF2 values. On average the absolute difference between the measured and estimated foF2 values was found to be $0.04 \mathrm{MHz}$ (an improvement 

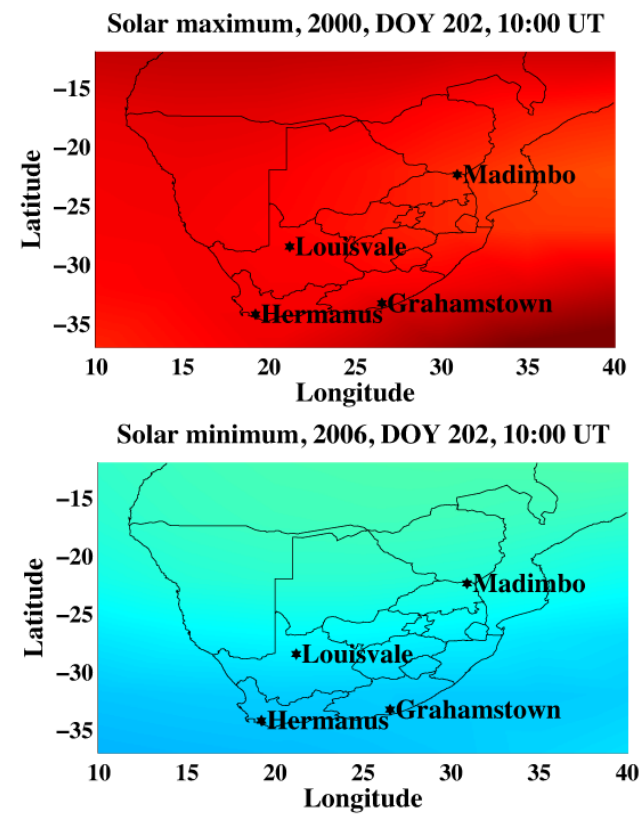

Figure 9. foF2 maps on an arbitrarily chosen DOY (202) during solar maximum (2000) and during solar minimum (2006).

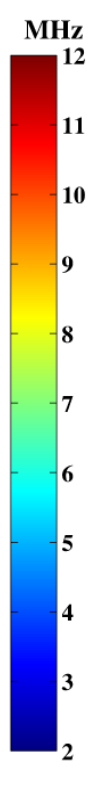


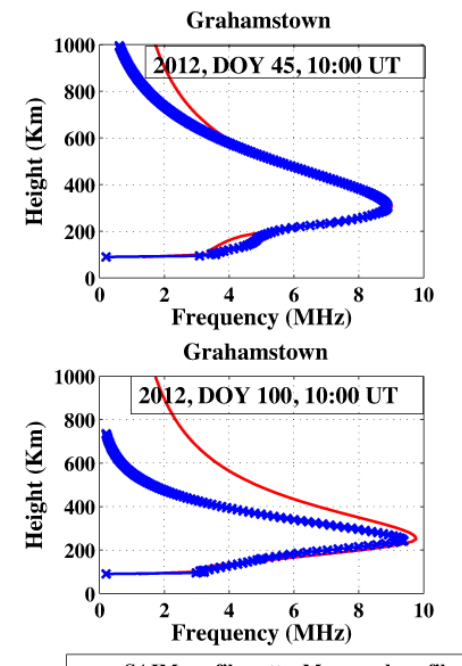

(a)

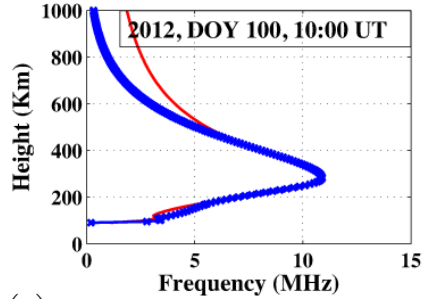

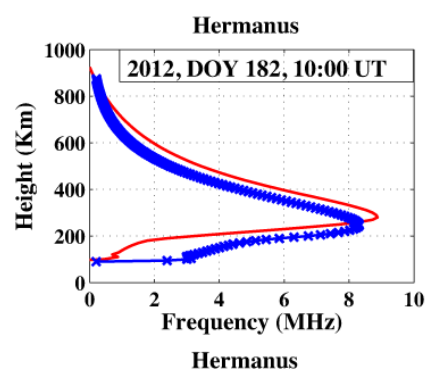

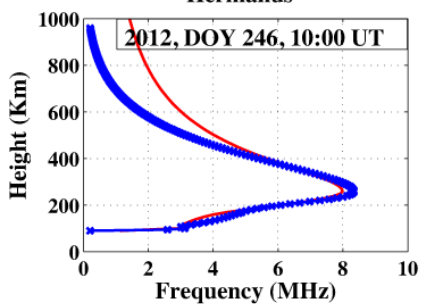

(b)
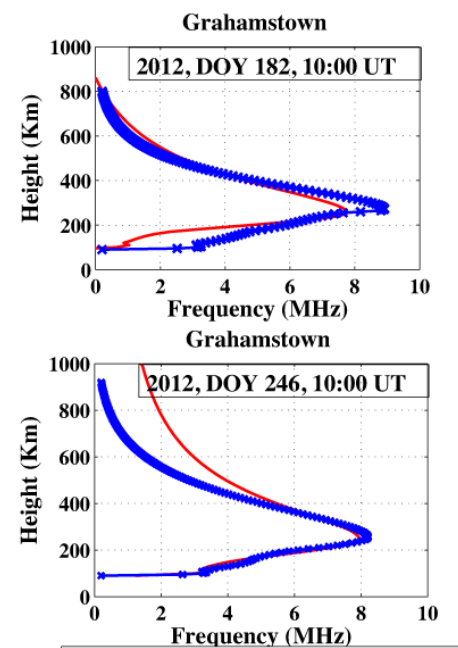

- SAIM profile $\rightarrow$-Measured profile of $75 \%$ ), compared to $0.16 \mathrm{MHz}$ by the previous version of SAIM developed by Okoh et al. [2010].

\section{Interface change}

A number of changes were made to SAIM's interface to make the map more user friendly. Figure 11a shows the new interface. The circled options are the added new functions.

$\mathrm{ftp}$ access: In the previous version of SAIM the ftp access details (ftp site, user name and password) of the ionosonde server were "hardwired" into the program. For the details to be changed, the source code had to be updated and a new standalone program created. The new interface "ftp login" option gives the end user the ability to change the access details without having to change the source code. If the access to the ftp server fails, the program lets the user know by displaying an error message "Connection to the ftp server failed" and then continues to generate the required map using the
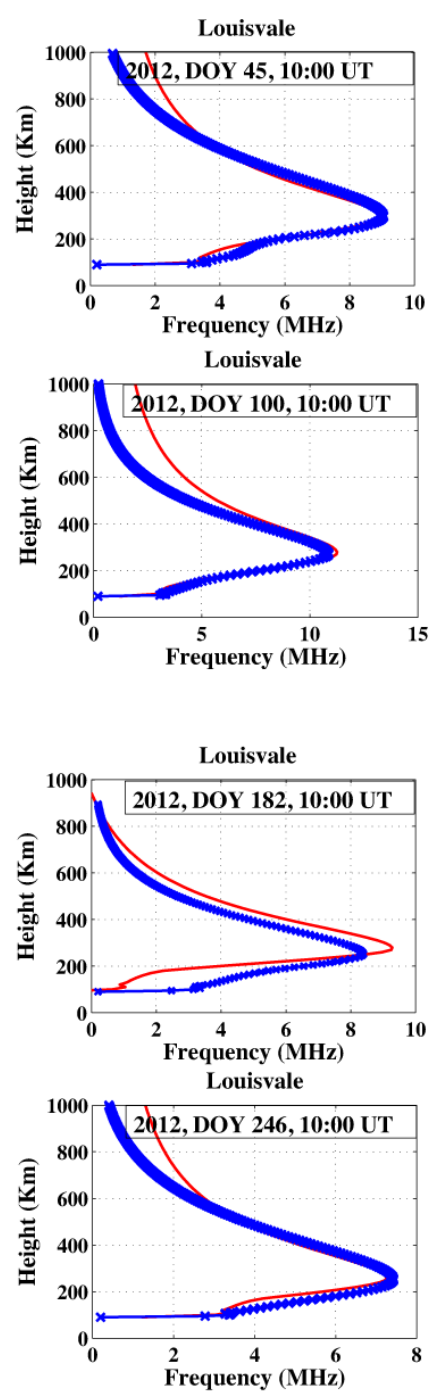

Figure 10. A comparison of SAIM profiles and ionosonde profiles from three stations: Hermanus, Grahamstown and Louisvale, for (a) summer (DOY 45) and autumn (DOY 100) in 2012, and (b) winter (DOY 182) and spring (DOY 246) in 2012. 



Figure 11. (a) The new SAIM interface. (b) An example of a comparison of profiles from different locations on the map. Time: 17:00 UT, 2010-09-27.

SABIM model and the IRI-2012 model. If the end user wishes to continue running the SAIM using the same access details for a given session, the radio button "Don't show again" is activated. The access details are then stored in the computer memory and invoked internally every time a new map is generated.

Hold on and Clear: This option lets the end user compare profiles from different locations on the map. Figure $11 \mathrm{~b}$ shows an example of a comparison of profiles from four locations on the map at 17:00 UT (15:00, SAST). If new plots are needed for the same running time, the "clear" option is used to clear the axes.

\section{Conclusion}

This paper has discussed the improvements and validation of the new version of SAIM. The SAIM was updated with the Hermanus ionosonde data, the IRI2012 model and SABIM version 5. These updates improved the performance of SAIM (estimation of foF2) by $75 \%$ over the previous version. The performance of the SABIM model was also validated for estimation of foF2 values over the South African region. The results show that the SABIM model outperforms the IRI-2012 model. During solar maximum and solar minimum, the SABIM model was found to perform $27 \%$ and $14.7 \%$ respectively, better than the IRI-2012 model. In addition, the SABIM version 5 model was also found to performs $16 \%$ better than its predecessors.

Thus, in recommendation, SAIM is a more accurate solution than single independent data sources for applications requiring ionospheric mapping over the South African region.

Acknowledgements. We wish to acknowledge the South African National Space Agency (SANSA) for providing the data used in the analysis. The data is accessible via various websites, including the Space Physics and Interactive Data Resource (SPIDR, http:/ / spidr. ngdc.noaa.gov/spidr/) and the Digital Ionogram Database (DIDBASE, http:/ / ulcar.uml.edu/DIDBase/). 


\section{References}

Adeniyi, J., D. Bilitza, S. Radicella and A. Willoughby (2003). Equatorial F2-peak parameters in the IRI model, Advances in Space Research, 31, 507-512.

Adewale, A., E. Oyeyemi, J. Adeniyi, A. Adeloye and O. Oladipo (2011). Comparison of total electron content predicted using the IRI-2007 model with GPS observations over Lagos, Nigeria, Indian Journal of Radio and Space Physics, 40, 21-25.

Bilitza, D., and B. Reinisch (2008). International reference ionosphere 2007: Improvements and new parameters, Advances in Space Research, 42, 599-609.

Bilitza, D., L.-A. McKinnell, B. Reinisch and T. FullerRowell (2011). The international reference ionosphere today and in the future, Journal of Geodesy, 85, 909-920.

CCIR (1966). Atlas of ionospheric characteristics, Report 340-1, 340-6, Comité Consultatif International des Radiocommunications, Genève.

Habarulema, J.B., L.-A. McKinnell and P.J. Cilliers (2007). Prediction of global positioning system total electron content using neural networks over South Africa, Journal of Atmospheric and Solar-Terrestrial Physics, 69, 1842-1850.

Habarulema, J.B., L.-A. McKinnell and B.D. Opperman (2011). Regional GPS TEC modeling; Attempted spatial and temporal extrapolation of TEC using neural networks, Journal of Geophysical Research, 116, A04314.

Habarulema, J.B., and L. McKinnell (2012). Investigating the performance of neural network backpropagation algorithms for TEC estimations using South African GPS data, Annales Geophysicae, 30, 857866.

Habarulema, J.B., L.-A. McKinnell, D. Buresová, Y. Zhang, G. Seemala, C. Ngwira, J. Chum and B. Opperman (2013). A comparative study of TEC response for the African equatorial and mid-latitudes during storm conditions, Journal of Atmospheric and Solar-Terrestrial Physics, 102, 105-114.

McKinnell, L.-A. (2003). A neural network-based ionospheric model for the bottomside electron density profile over Grahamstown, South Africa, Ph.D. thesis, Rhodes University, Grahamstown.

McKinnell, L.-A., and A.W. Poole (2004a). Neural network-based ionospheric modelling over the South African region, South African Journal of Science, 100, 519-523.

McKinnell, L.-A., and A.W.V. Poole (2004b). Predicting the ionospheric F layer using neural networks, Journal of Geophysical Research, 109, A08308.

McKinnell, L.-A. (2008a). Sabim model version 3.0: A bottomside ionospheric model for the South African region, Tech. rep.

McKinnell, L.-A. (2008b). The Progress of the South African Ionosonde Network, AIP Conference Proceedings, 974, 47-51.

McKinnell, L.-A., and P. Sibanda (2010). Sabim model a bottomside ionospheric model for the South African region, Tech. rep., Hermanus Magnetic Observatory/Rhodes University.

Miró Amarante, G., M. Cueto Santamaría, K. Alazo and S. Radicella (2007). Validation of the STORM model used in IRI with ionosonde data, Advances in Space Research, 39, 681-686.

Okoh, D.I. (2009). Developing an ionospheric map for South Africa, Master's thesis, Rhodes University, Grahamstown.

Okoh, D., L.-A. McKinnell and P. Cilliers (2010). Developing an ionospheric map for South Africa, Annals of Geophysics, 28, 1431-1439.

Okoh, D., A. Eze, O. Adedoja, B. Okere and P. Okeke (2012). A comparison of IRI-TEC predictions with GPS-TEC measurements over Nsukka, Nigeria, Space Weather: The International Journal of Research and Applications, 10, S10002.

Opperman, B.D., P.J. Cilliers, L.-A. McKinnell and R. Haggard (2007). Development of a regional GPSbased ionospheric TEC model for South Africa, Advances in Space Research, 39, 808-815.

Poole, A.W., and L.-A. McKinnell (2000). On the predictability of foF 2 using neural networks, Radio Science, 35, 225-234.

Poole, A.W., and M. Poole (2002). Long-term trends in foF2 over Grahamstown using Neural Networks, Annals of Geophysics, 45, 151-161.

Reinisch, B.W., I.A. Galkin and G. Khmyrov (2012). Ionosonde Data Exchange SAO.XML Data Model 5.0, University of Massachusetts Lowell Center for Atmospheric Research, Lowell, MA.

Rush, C., M. Fox, D. Bilitza, K. Davies, L. McNamara, F. Stewart and M. PoKempner (1989). Ionospheric mapping - An update of foF 2 coefficients, Telecommunication Journal, 56, 179-189.

Ssessanga, N., L.-A. McKinnell and J.B. Habarulema (2014). Estimation of foF2 from GPS TEC over the South African region, Journal of Atmospheric and Solar-Terrestrial Physics, 112, 20-30.

\footnotetext{
Corresponding author: Nicholas Ssessanga, Chunganam National University (CNU), Department of Astronomy and Space Science, Daejeon, South Korea; email: nikizxx@gmail.com.

(C) 2015 by the Istituto Nazionale di Geofisica e Vulcanologia. All rights reserved.
} 